https://doi.org/10.48009/2_iis_2007_186-192

\title{
APPLICATION OF WEB 2.0 TECHNOLOGY TO THE ENTREPRENEURIAL PROCESS
}

\author{
Rubayet Salam, University of Texas at Tyler, rsalam2@patriots.uttyler.edu \\ Greg Clary, Texas A\&M University, g-clary@tamu.edu \\ Isaura Flores, University of Texas at Tyler, isaura07@suddenlink.net
}

\begin{abstract}
Information systems have become an integral part of social, professional, educational, and business environments. Technology has shown its mark through companies such as MySpace, YouTube, Ebay, Blackboard, Amazon, and Facebook. The Internet has enabled people to pursue unique business opportunities and create social phenomena and trends online. Technology that is at the root of new business trends and opportunities is Web 2.0 software, which is the next generation of web technologies that utilize the Internet as a platform to emphasize networking, collaboration, and sharing amongst users. This paper outlines a system to bring innovation to the process of supporting entrepreneurs and their communities by resource providers through the application of Web 2.0 software. The model characterizes how technology can be leveraged to streamline the business development process in order to route entrepreneurs through the various business development and growth life cycle stages with a selfsustaining network. It is through both vertical and horizontal communication that entrepreneurs will proceed through the various stages of business development and receive the technical assistance to address the many questions and problems facing entrepreneurs. The individualized network allows entrepreneurs to obtain timely and pertinent information and training that directly applies to their individual needs.
\end{abstract}

Keywords: Information Systems, Entrepreneurship, Web 2.0, Social Network

\section{INTRODUCTION}

A new revolution has begun in the computer industry and the entrepreneurial opportunities are more visible due to information access. The revolution, Web 2.0, is best characterized by Tim O'Reilly when he said, "Web 2.0 is the business revolution in the computer industry caused by the move to the Internet as platform, and an attempt to understand the rules for success on that new platform." As such, it is necessary to develop technology utilizing the Internet to aid entrepreneurs with their business endeavors. The Internet can provide the medium for entrepreurs to network, collaborate, and share amongst each other as well as receive information from resource providers in order to streamline and expedite the business development and growth life cycle from idea inception to implementation and growth. The necessity for a social network that works as an aid to bring pertinent information to individual entrepreneurs is on the rise, especially when so many entrepreneurs are not even starting a business due to misinformation, misguidance, or not enough information in the respective local communities.

In order to outline a social networking system that connects entrepreneurs with resource providers and each other, we will use a case study of the Texas Center for Rural Entrepreneurship (TCRE) that will clearly show the importance, necessity, and benefits of creating such a social network. The TCRE is an established non-profit organization created by rural entrepreneurs, economic development leaders, nonprofit organizations, and local, state and federal government entities. The TCRE was created to establish neutral ground to facilitate the delivery of educational and technical support to meet the needs of rural entrepreneurs and organizations supporting entrepreneurs and the entrepreneurial spirit in rural Texas. The organization serves as an on-line tool to support the coordinated delivery of services and information between resource providers and the rural businesses and communities they serve. The website (www.tcre.org) is fully functional and designed to help entrepreneurs through each stage of business development and growth.

\section{Current TCRE Model}

TCRE has a fully functional business plan, which includes resource providers located statewide. For individuals, businesses, and possible resource providers interested in joining TCRE, the access process is simple and requires submitting a profile. The first step in the profile is to determine which area of Texas one is interested in creating a business, or in getting help with an already established business. 
There are 28 areas of Texas which are the following: Panhandle, South Plains, North Texas, North Central Texas, Tarrant County, Dallas, North East, East Texas, West Central, Upper Rio Grande, Permian Basin, Concho Valley, Heart of Texas, Capital Area, Rural Capital, Brazos Valley, Deep East Texas, South East Texas, Golden Crescent, Alamo, South Texas, Coastal Bend, Lower Rio Grande, Cameron County, Texoma, Central Texas, Middle Rio Grande, and Gulf Coast.

The next step in the process is to register the name, business information, specialties and submit the form electronically to TCRE. This enables the entrepreneur or business resource to access to access the areas on the website pertaining to business development.

After registration, access to resource providers for the area submitted in the profile is available. The East Texas area pulls up 20 different resource providers willing to help entrepreneurs in the business process. Participants can directly contact resources that are beneficial to them, or can fill out one of several forms to request assistance from TCRE. A form is available to request help for general or capitalization assistance. The forms then initiate communication with TCRE administration to link the applicant with the appropriate public or private entity that can address the request.

\section{Problem Definition}

The website is extensive and has involved a massive amount of work to develop it to the point where it is now beneficial to the end user. The problem for TCRE is that there is a large amount of physical work to be done for each new registrar. At this time, there is not a way to track an entrepreneur as they go through the new business process. There is no way of knowing if they linked up with a resource provider and if the resource provider followed up with the entrepreneur. Therefore, there is a necessity for a tool to streamline the business development and growth process and ease the entrepreneur's efforts in accomplishing their goal. The solution will be in the form of a portal that would allow resource providers and entrepreneurs to register, be automatically routed to where they need to go, and track and assist in every stage of the process. This would be a selfsustaining customer based network that would utilize the Internet as the medium for connecting the entrepreneurs with each other and the resource providers.

\section{Texas Self-Sustaining Entrepreneurial Network Model}

The Texas Self-Sustaining Entrepreneurial Network (TSEN) model is a blue print of the customer relationship management system that will be used to route entrepreneurs through the business development and growth life cycle stages. The model is defined as a system flow based on an identified business development and growth life cycle with 8 stages in hierarchal order. The stages are as follows in hierarchal order: Idea creation and business definition, developing an effective business plan, laws and regulations, funding, establishing business structure, implementation of business, and outflow. Each stage includes resources providers that will aid and guide entrepreneurs through that particular phase in the business development and growth life cycle. An entrepreneur will be able to traverse through the TSEN system flow, which is a cyclical process, based on business needs.

Figure 1 - TSEN System Flow

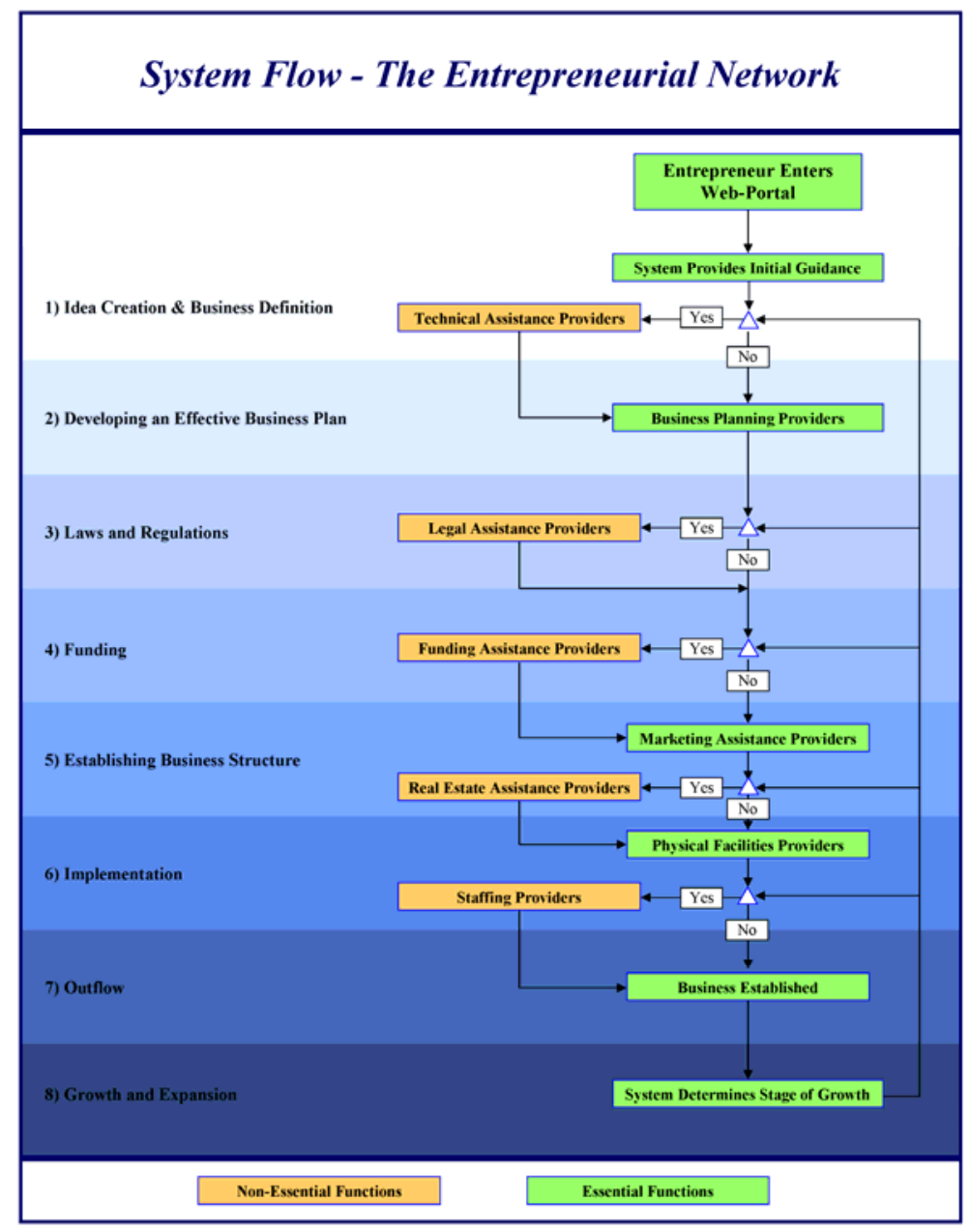




\section{Scope}

TSEN is a network that will be a tool for entrepreneurs to direct them to the service providers. It will also be used to track flow of entrepreneurs through the system and inform TSEN of any bottlenecks. The TSEN system provides the most efficient path to resource providers; thus expediting the process of business development and growth given the access to necessary and relevant information.

\section{Objectives}

The main objectives of the TSEN system are as follows:

- Define connections between the various resource providers by having them in the system.

- $\quad$ Attract entrepreneurs, have them enroll and enter the system, navigate them across the network nodes to obtain all the resources needed to successfully launch their business.

- Define the entrepreneur's initial problem, which will identify the initial stage where the entrepreneur should enter the system..

- $\quad$ Provide entrepreneurs with the tools necessary to evolve through the business development and growth life cycle stages.

- Provide entrepreneurs with the direction necessary to evolve through the business development and growth life cycle stages.

- Identify and solve problems that hinder entrepreneurs from smoothly passing from one stage to next in business development and growth life cycle.

\section{Limitations}

The TSEN system is a tool to help entrepreneurs in their endeavor to establish and grow their businesses. It is not meant to be used by the entrepreneurs as a substitute for sound research in creating and growing their businesses.

\section{$\underline{\text { Stages of Evolution }}$}

As mentioned earlier and Figure 2 displays, there are different stages of the business development and growth life cycle that an entrepreneur will have to traverse through. These stages define the paths in the system that entrepreneurs are able to navigate based on a set of criteria that allows the system to profile and connect the entrepreneurs with the appropriate service providers in the respective stages. The criteria used to direct entrepreneurs through the various stages of the business development and growth life cycle are based on the entrepreneurs' needs. As an entrepreneur successfully passes through a stage, a new set of criteria is used to direct him or her along the path.

The different stages include multiple nodes that represent the categories of services required by the entrepreneurs that are offered by the various providers. In each stage, there are the distinguishing characteristics of the various resource providers in how they interact with different entrepreneurs. For example, an entrepreneur interested in building an Ecommerce business may need different types of capital than an entrepreneur interested in becoming a manufacturer. Figure 3 shows a comparison of the different types of capital that an entrepreneur would require based on his or her choice of industry.

Figure 3 - Capital Required by Entrepreneur Based on Industry

\begin{tabular}{|l|l|}
\hline E-commerce & Manufacturing \\
\hline Personal Notes & Investors \\
\hline Small bank loans & Large loans \\
\hline & Grants \\
\hline
\end{tabular}

\section{TSEN User Roles and Respective System Flow}

Based on the different stages of the business development and growth life cycle and the criteria for entrepreneurs to traverse through each stage, the system can be outlined and user roles identified. There are four different user roles defined in the system that will interact with the system and each other. The roles are defined based on different sets of criteria. Two roles are automatically assigned and two roles are manually assigned.

The roles of entrepreneur and provider are automatically assigned to users based on the assessment of the users at registration. Essentially, actual entrepreneurs and providers will be profiled at registration and assigned to either entrepreneur role or provider role. In addition, these particular roles can become inactive. If a resource provider has not logged in for a specified period of time, the account will be inactivated and an email will be sent requesting the provider to reactivate the account by simply logging into the system. The same is true for entrepreneurs with a different specified amount of time.

The other two roles, coach and administrator, are assigned according to the user's role in the TEN 
organization. A coach is someone who is part of the TEN organization that will oversee daily operations and identify opportunities and problems with the overall network of entrepreneurs and service providers. An administrator is a technical person in charge of managing and maintaining the TSEN system.

The various roles and their respective system flows are defined in the following:

\section{Entrepreneur's Role}

An entrepreneur is the client in respect to the TSEN system. He or she will receive a service. In this case, an entrepreneur will register and be allocated to a certain stage within the business development and growth life cycle. He or she will then begin to proceed through the TSEN system, which is based on the Texas Self-Sustaining Network Model.

In any given node or category of service provider (e.g. Capital -> Banks, Credit Unions) in the TSEN system, an entrepreneur is provided with a list of resource providers, which can be sorted by feedback ranking, physical distance, and cost. An entrepreneur chooses a resource provider and the system queues the entrepreneur to that specific resource provider.

A queue is created when an entrepreneur indicates intention to visit a resource provider. A resource provider is able to note the entrepreneur's account and clear the queue on meeting with the entrepreneur. If the queue is not cleared within a specified amount of time, the entrepreneur is sent an email reminding him or her to either attend the appointment or rate the service of provider.

An entrepreneur logs back into the system (if entrepreneur does not log back in within a specified amount of time, he/she is sent an email reminder), he/she rates the service provider and chooses to go to the next step or see an alternate resource provider within the same step.

\section{Provider's Role}

A provider is the one who provides the service to the client in respect to the TSEN system. A provider has three functions in terms of the TSEN system. One function is to clear or validate the entrepreneur once he or she has met with the provider. The second function is to review and annotate entrepreneur's account. The third function is to keep track of the respective queue and contact entrepreneurs when an abnormal amount of time has passed from entering the queue.

\section{Coach's Role}

A coach is the report analyzer in respect to the TSEN system. Since the coach role is to be assigned to someone who is part of the TSEN organization that will oversee daily operations and identify opportunities and problems with the overall network of entrepreneurs and service providers, the coach role will have reporting capabilities. The view of the reports will be based on constraints. The number and depth of the various reports required will need to be determined. A requirements analysis will need to be conducted in order to determine the specific reports that will be necessary to allow the user to assess opportunities and problems and be able to make decisions.

Some definite reports that will be required pertain to rate of flow (how fast entrepreneurs get through system), providers' ratings, and bottleneck formation. Report for the bottlenecks will be based on criteria of the number of people in a queue and the length of time spent in the queue. A list of providers would be identified if the maximum allotted time and people were exceeded.

\section{Administrator's Role}

An administrator is the technical role that will be able to manage and maintain the backend of the system, especially pertaining to parameter definitions and user permissions. The administrator role is to be determined based on decisions such as contracting or hiring due to the technical nature of the role. Different types of systems and different development companies assign different roles for the system administrator depending on their use of logic. A requirements analysis will need to be conducted in order to determine the tasks of the administrator role.

\section{Additional Functionality of TSEN System}

A rating system functionality for service providers should be incorporated in to the TSEN system. The purpose of the rating system is to enable entrepreneurs the ability to choose more efficient resource providers based on their respective ratings. A rating system provides for a basis of checks and balances within the system. This is allows the TSEN system to be self-monitored. Service providers rated below a set required rating may warrant attention from the TEN organizations. 
Rating/feedback system includes the Likert Scale for dimensions such as friendliness, quality of support, technical expertise, TBD, and a section for comments.

\section{Optional Functionality of TSEN System}

A helpdesk/technical support system may be provided within the TSEN System in order to provide live help and feedback to entrepreneurs. This would allow the TSEN System to incorporate a relationshipbuilding medium whereby it becomes more animated.

The helpdesk/technical support system includes searchable frequently asked questions. In addition, a user, at any point, can request support via online chat. Chats can be routed to TSEN technical support or geographically located support centers in entrepreneur ready communities. Geographic routing is based on profile of registered users (entrepreneur's location). Guests are automatically routed to TSEN technical support.

\section{Alternate Use for TSEN System}

The TSEN system can be used as a medium for entrepreneur ready communities to advertise to potential or existing communities. Entrepreneur ready communities will be able to advertise their core competencies and resources available to entrepreneurs moving to the respective city. For example, if the entrepreneur were in Austin, then advertisement pertaining to the IT field would be advertised. In addition, resource providers that are for profit organizations could also advertise to the entrepreneurs. For example, the system could advertise engineering capital to a manufacturing company like Trane.

The TCRE is a service network streamlining the process entrepreneur's face when trying to gain the resources to launch their ideas or businesses. It is designed to link entrepreneurs to resource partners who can provide assistance with effectively acquiring capital, management, and leadership resources. It is designed to monitor the current position of the entrepreneur in the system and guide them to the next step and see that the process is completed. With an understanding of the function of the TCRE and the Network, we can then turn to how to market the product, what expenses are associated with the product, and how to generate revenue to sustain it. The purpose of this section is to outline marketing strategy and revenue possibilities necessary for the sustainability of TSEN.

\section{Internet}

The Internet is the platform for a social network such as TSEN. The Internet allows for communication, collaboration, and sharing. The Internet also offers many effective ways to reach the masses. "By 2005, Internet penetration in the United States will represent $66.7 \%$ of the population of people who are age 14 and older." (Kumar and Shaw, p.30) The president of the National Marketing Federation places great emphasis on the Internet as it offers some of the least expensive and effective marketing available. There are several forms of Internet advertising, which include but are not limited to web pages, banner ads, search, and webcasts. "The steady growth of online advertising is a clear indication that marketers continue to believe in the opportunities and effectiveness that this medium delivers in reaching and engaging their customers," said Greg Stuart, CEO, Interactive Advertising Bureau, New York. IAB projected that first-quarter (2006) online ad spending was closer to $\$ 4$ billion, a rise of $38 \%$. (Hein, p.565) As the Network involves web based technology, the website will need to be marketed. The below graph illustrates how the United States invests in online advertising. (Kumar and Shaw p.31) 


\section{U.S. online advertising spending}

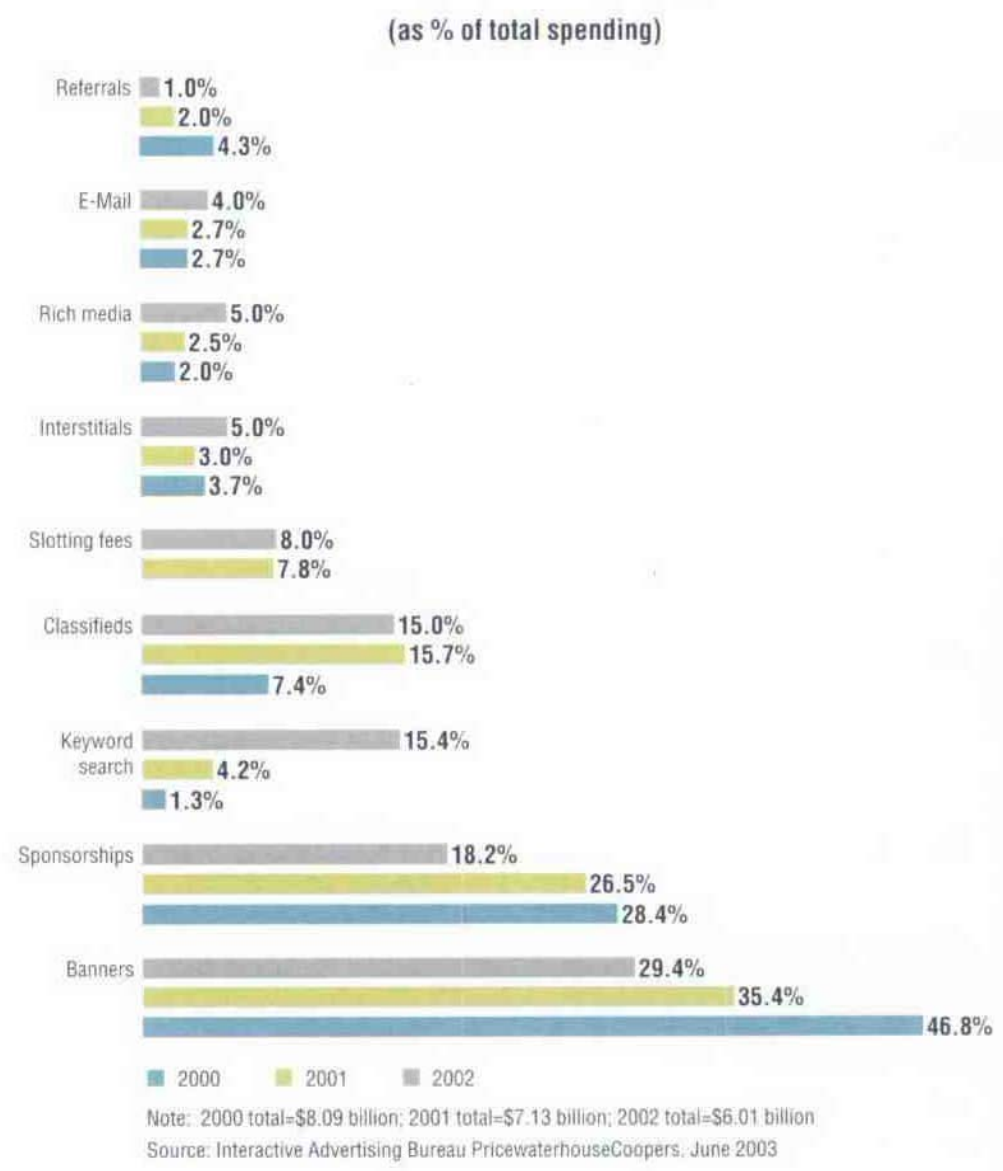

Due to the vast spending in online advertisements, TSEN will be able to generate increasing revenues to sustain its growth through advertisement offerings on its website.

\section{Selling Advertisement Space on the TCRE Website}

The Network will have appeal to competing resource providers providing the same service. Consequently, the Network's website should be utilized for generating revenue through advertisements in the form of banner ads or other similar media. Couple this with the fact that Internet advertising is on the rise, selling advertising space on the website should be easy to achieve. "As companies realize the effectiveness of online marketing in reaching targeted audiences with measurable results, they will boost their spending in this medium in 2006. Research company eMarketer estimates that online ad spending in the U.S. will reach $\$ 15.6$ billion in 2006, up from $\$ 12.9$ billion this year. (Maddox, p.28)

\section{Entrepreneurs}

The purpose of the Network is to make the process of launching a business easier for entrepreneurs. When obtaining feedback about the concept of TSEN from a bank in the business of commercial lending, one of the gentlemen, who was once in the small business loan business, made a comment about the process of starting a new business. Perhaps the process to start a business should not be easy? If one has an idea and thinks it will be a successful business, how willing are they to work for that goal? The evidence would suggest that those willing to spend some time and perhaps money to launch their business would be more successful than those who did not.

Since the Network takes some of the work out of the process of launching a new business, perhaps entrepreneurs would be willing to pay a modest fee for gaining access to it. The modest fee would need to be determined based on utilization and the financial requirements of the TCRE. The fee could 
be based on the movement of the entrepreneur from node to node along the Network or be based on the assumption all nodes will be crossed and the process for launching a business completed.

If the later alternative is considered, it would accomplish two things. First, it would generate more revenue by collecting dollars for the whole process whether the entrepreneur completes the process or not. Second, it becomes a larger consideration for the entrepreneur, with regards to their commitment level towards their business venture, thereby promoting more successful endeavors. However, it should be noted that the most successful social networks are ones that have a business model that do not charge the users of the site but rather generate revenues through advertising. It is the concept of free market and allowing the users to dictate their own success rate that is of the utmost importance to the survival of any social network.

\section{CONCLUSIONS}

It is important to emphasize the primary goal of TSEN. TSEN is the social network that will enable entrepreneurs to network, collaborate, and share with other entrepreneurs and resource providers. Entrepreneurs will be guided through the business development and growth process through online decision-making software using the system flow in Figure 1.

The primary goal of TSEN is to help entrepreneurs implement and sustain their businesses which will lead to economic growth in terms in employment, GDP, and general growth of cities - especially rural cities. In addition, new business creation leads to government earnings through taxes.

As rural cities grow, economic and social burdens will be alleviated in nearby metropolitan areas; thus leading to more social and economic stability overall.

\section{REFERENCES}

1. Bhide, Amar. (1992). Bootstrap Finance: The Art of Start-Ups. Harvard Business Review, 70 (6), 109-117.

2. Colwell, Peter F., Kahn, Charles M. (2001) Journal of Real Estate Finance \& Economics, 23 (3), 267-295.

3. Cusumano, Michael. (2005). Google: What it is and What it is Not. Communications of the ACM, 48 (2), 15-17.

4. Gangemi, Jeffrey. (2006). Building a Web Presence on the Cheap. Business Week Online.
5. Hein, Kenneth, Wasserman, Todd, Brandweek. (2006). As Web Matures, Sites Grow Up Too. 47 (25).

6. Hitt, Michael, Ireland, R. Duane \& Hoskisson. (2007). Strategic Management. New York, NY: South-Western College Publishing.

7. Krajewski, Lee and Ritzman, Larry (2005) Operations Management pp. 345-347.

8. Kuhnel, Brenda. (2000). Retire and Get Busy: Start A Business. Consulting and Specifying Engineer, 28 (1), 15.

9. Kumar, V., \& Shah, Denish. (2004). Pushing and Pulling on the Internet. .Marketing Research, 16 (1), 28-33.

10. Maddox, Kate. (2005). Marketers anticipate online spending rise. $B$ to $B, 90$ (16)

11. O'Reilly, Tim. (2006). Levels of the Game: The Hierarchy of Web 2.0 Applications. O'Reilly radar.

12. Rich, Stanley R. and Gumpert, David E. (1985). Growing Concerns: How to write a winning business plan. Harvard Business Review, 63 (3), 156-162.

13. Sahlman, William A. (1997). How to Write a Great Business Plan. Harvard Business Review, 75(4), 98-108.

14. Summerfield, Brian. (2005). Lift-Off! How to Launch a New Business. Certification Magazine, 7 (8). 